\title{
Existence, Proof and Truth-Making: A Perspective on the Intuitionistic Conception of Truth*
}

\begin{abstract}
Truth-maker analyses construe truth as existence of proof, a well-known example being that offered by Wittgenstein in the Tractatus. The paper subsumes the intuitionistic view of truth as existence of proof under the general truth-maker scheme. Two generic constraints on truth-maker analysis are noted and positioned with respect to the writings of Michael Dummett and the Tractatus. Examination of the writings of Brouwer, Heyting and Weyl indicates the specific notions of truth-maker and existence that are at issue in the intuitionistic truth-maker analysis, namely that of proof in the sense of proof-object (Brouwer, Heyting) and existence in the nonpropositional sense of a judgement abstract (Weyl). Furthermore, possible anticipations in the writings of Schlick and Pfänder are noted.
\end{abstract}

1.

Michael Dummett writes:

From an intuitionistic standpoint . . an understanding of a mathematical statement consists in the capacity to recognize a proof when presented with one; and the truth of such a statement can consist only in the existence of such a proof. ${ }^{1}$

It is the purpose of the present paper to offer some remarks of a philosophical and historical nature on this conception of truth and its meaning-theoretical use.

2.

The intuitionistic scheme

$A$ is true

$=$

there exists a proof of $A$

can profitably be construed as a special instance of the general truth-maker analysis of truth:

$A$ is true

$=$

there exists a truth-maker for $A$, which can best be seen as an attempt at giving content to the metaphors involved in the so called correspondence theory of truth. ${ }^{2}$

In general, a truth-maker analysis is given in terms of three items, namely,

(1) the (category of) truth-bearers $A$,

(2) for each object $a$ of the category of truth-bearers, a category $T M_{A}$ of truth-makers for $A$,

and finally,

(3) the relevant notion of existence for the category $T M_{A}$.

Leibniz's Satz vom Grunde provides a case in point:

A true proposition is one where the predicate is contained in its subject, or, more generally, whose consequent is contained in its antecedent, and it is therefore necessary that there should be some connexion between notions of the terms, i.e. that there should be an objective foundation from which the reason for the proposition can be given, or, an a priori proof can be found. ${ }^{3}$

Here the truth-bearer is a proposition in the oldfashioned sense, that is, a judgement of subject/copula/ predicate form

$S$ is $P$

Leibniz construes all truth, whether necessary or contingent, as analytic. The proposition is true when the predicate is contained in the subject, such containment being made evident from a certain ground, or reason, namely a possibly infinite a priori proof of the judgement in question, consisting of (possibly infinite) resolutions of the concepts $S$ and $P$ into primitive components. A truth of reason has a finite proof, whereas the resolution proceeds to infinity in the case of a truth of contingent fact. The truth-maker is this a priori proof and the relevant notion of existence is resolvability (in the mind of God). Modern truth-maker analyses were offered in the early parts of the present century by 
Husserl, Moore, and Russell, using as truth-makers, for example, facts, complexes and Sachverhalte. The most elaborated of these modern attempts, surely, is that presented by Wittgenstein in the Tractatus. ${ }^{4}$

\section{3.}

The particular properties of a given truth-maker analysis will obviously depend on the three specific choices made as to the truth-bearers, their truth-makers, and the appropriate mode of existence for the chosen truthmakers. Clearly, in view of the rich variety of truthmaker analyses that has been offered, one cannot expect to establish too many general theses, applicable to any truth-maker analysis, from the very formulation of the generic truth-maker scheme itself.

In the Dummett passage quoted above, the link between truth- and meaning-theoretical issues is faced squarely from the outset, and the meaning of a sentence is, of course, commonly formulated in terms of truth conditions. These, on the other hand, are given in terms of a notion of truth that is construed according to the truth-maker analysis in question. Therefore, on the hypothesis that meaning is given in terms of truth conditions, the truth-maker analysis will be subjected to meaning-theoretical constraints. Such constraints, then, provide further conceptual structure which might enable us to formulate some general insights concerning the truth-maker analysis of truth.

\section{4.}

One remark concerning truth-maker analyses that can be made bears on the application of the notion of identity to truth-bearers. An appropriate notion of identity for truth-bearers can be obtained without effort given the truth-maker analysis. An identity criterion is readily formulated in terms of the truth-makers:

$A$ is the same truth-bearer as $B$ iff

the truth-maker categories $T M_{A}$ and $T M_{B}$ coincide

An alternative, essentially equivalent choice would be to use instead:

$A$ is the same truth-bearer as $B$ iff

every truth-maker for $A$ is a truth-maker for $B$, and vice versa.
When the truth-bearers are propositions, the above constitutes a simple solution to the old Quinean challenge of providing a criterion of identity for propositions.

A second general point can be made concerning the notion of existence that is involved in a meaningtheoretically constrained truth-maker analysis. Here the meaning of a sentence $A$ is laid down in terms of its truth condition

$A$ is true.

Thus, on pain of a vicious regress of ever-descending meaning-explanations, the predicate

$\ldots$ is true

cannot be propositional in nature. In other words, it is not a propositional function formulated in the language from which the sentences are taken whose meaning is explained using the predicate in question. When combined with the truth-maker analysis this yields the result that the existence involved in such an analysis is not that of the existential quantification

$$
\exists x P(x) \text {. }
$$

It must be observed first that there is no such thing as the meaning of this quantifier independently of its occurrence in existential propositions; on the contrary, the meaning of the quantifier is explained as part of the existential proposition having such and such a truthcondition. Furthermore, the proper form of the quantification is

$$
(\exists x \in D) P(x),
$$

since the usual, model-theoretic explanation of the semantics of the quantifier suppresses the domain of quantification, owing to the separation of syntax and semantics. Here when the quantified formulae express propositions, rather than serve as the formal objects of metamathematical study, the domain of quantification has to be explicitly included. The meaning of the existential quantifier $\exists$ is accordingly explained in terms of the conditions under which $(\exists x \in D) P(x)$ is true.

On the truth-maker analysis this truth condition is analysed as:

there exists a truth-maker for $(\exists x \in D) P(x)$.

If the existence involved here were itself to be expressed by means of an existential quantifier, firstly, in order that the quantifier be applicable, the relation of truth- 
making between the truth-maker and the true proposition would have to be a propositional function. Secondly, an infinite regress would arise:

$(\exists z \in$ the category of truth-makers for $(\exists x \in$ $D) P(x))$

[the relation of truth-making obtains between $z$ and the proposition $(\exists x \in D) P(x)]$,

since the first existential quantifier $\exists z$ has yet again to be expressed in terms of the truth-condition for an existentially quantified proposition, and so on. Thus, the notion of existence at issue here is not that of the existential quantifier. Accordingly, also the status of the relation of truth-making between the truth-bearer and the truth-maker is sub judice and one cannot expect it to be that of a propositional function: if it were, it would immediately combine with the existential quantifier to yield a proposition of the rejected, regress-infested type.

\section{5.}

Phenomena related to, or originating in, this unusual status of the relation of truth-making have been noted by Dummett in his comments on an argument for the undefinability of truth, that is, against the possibility of a general characterization of the concept of truth. The argument runs roughly as follows:

(i) In order to find the condition for a proposition $p$ to be true, a general characterization of truth is applied to $p$.

(ii) In order to apply the general characterization to $p$, one needs to know what proposition $p$ is.

(iii) In order to know what proposition $p$ is, one must know the condition for $p$ to be true.

(iv) Thus, in order to apply the general truth-characterization to the proposition $p$, one must already know the outcome of this application.

Applying this to sentences, Dummett concludes that "if you know what a sentence means, you do not need any criterion for its truth, and, if you do not know what it means you cannot possibly apply any such criterion".

Dummett then notes that "what the argument shows is that the concept of truth is intricately bound up with the concept of meaning; no philosophical elucidation of either concept is to be had which does not at the same time provide an elucidation of the other one". The point gets rephrased as:
If to grasp the meaning of a sentence involves knowing when it ... is true, then this knowledge must involve knowing what it is, in general, for a sentence . . . to be true. To know this is neither necessary or sufficient to know, of every particular sentence, under what conditions it is true. It must, rather, involve knowing how in all cases the concept of truth is related to that of meaning. To be more exact, we ought here to speak of an implicit grasp of the connection between the concepts of meaning and of truth, rather than of a knowledge of it. ${ }^{6}$

This connection between meaning and truth can take either of two forms. It is direct when meaning is given in terms of truth. The connection will be mediated when meaning is ultimately given in terms of another notion. In this second case, as Dummett rightly notes, there has to be a uniform manner of deriving the notion of truth from the latter notion in terms of which meaning is then ultimately explained:

we need to distinguish between a feature of an expression which is dependent upon its meaning and one that is actually part of that meaning. This distinction underlies our intuitive inclination to take the meaning as something we confer on an expression, ....

If some feature of an expression is merely dependent on its meaning, then it did not have to be conferred and cannot be altered; that is, it cannot be altered without altering something else to which it is responsible, and from which it derived. If, however, it is actually part of the meaning, then, in the sense in which it is we who make our words mean what they mean, we could alter it without there being anything else which we should, as it were, have to alter first. ${ }^{7}$

In Dummett's terminology, the condition for a sentence to be true will be dependent on the meaning of the sentence in question, but it will not be part of that meaning. Meanings are then, ultimately, given in terms of truth-makers and it is the relevant truth-maker that is part of the meaning of the sentence. The truth-maker scheme provides a "general characterisation of that feature (i.e. truth G.S.) in terms of whichever other feature has been chosen as that by means of which the meaning is given (i.e. the relevant notion of truth-maker G.S.). . . This characterisation will constitute a uniform manner of deriving the former from the latter."

6.

Consider a truth-maker analysis of sentential truth. The above points made by Dummett can then be recast using terminology derived from Wittgenstein's Tractatus. In that work, the primary category of truth-bearer is that of an elementary proposition (Elementarsatz). (Other 
truth-bearers, namely the objects of the category of propositions, are obtained recursively from the elementary propositions by means of (generalized) truthfunctional combinations. For the purpose of the present discussion of the Tractatus, I will use the term "proposition" for the elementary propositions.) The propositional sign, which is itself a fact in the world, is made into a symbol, with meaning, by being placed in an internal projective relation to the world, which associates simple names with objects. The symbol comprises the material sign, as well as the projective relation to the world, but not what is projected. What is projected, or presented, is a state of affairs (Sachverhalt). Thus, given a meaningful (elementary) sentence, that is, given a proposition, it is possible, by virtue of its meaning, to read off, am Symbol allein, what has to be the case if the proposition is true, namely that the presented state of affairs obtains (German: bestehen). This is just what a meaningful sentence is: a means for presenting what has to be the case if it is to be true. What has to be the case, if it is to be true, it is possible to determine from the symbol itself, by virtue of its being a symbol: internal properties and relations can be read off from the symbols themselves, and the relation between proposition and state of affairs is an internal one. Whether, on the other hand, the proposition is indeed true, whether what has to be the case if the proposition is to be true is in fact the case, is not internal to the symbol, but is something which can be found out, if at all, only by comparing the proposition with the world. On this Tractarian truth-maker analysis of truth and meaning, the category of truth-makers corresponding to a proposition is the singleton category consisting solely of the state of affairs presented by the proposition in question, and when this state of affairs obtains the proposition is true (4.25).

Finally, let us note that the truth-maker analysis offered in the Tractatus does agree with the above two general points concerning truth-maker analyses. In accordance with the first point concerning the truthmaker definability of truth-bearer identity, the presented state of affairs does determine the (sense of the) elementary proposition (4.2-4.21). In this connection, also the following theses, concerning the sense of the (complex) proposition, rather than just that of the elementary proposition, are highly congenial:

I will give the name truth-grounds of a proposition to those truth-possibilities of its truth-arguments that make it true.

(5.101c)
If he truth-grounds that are common to a number of propositions are at the same time truth-grounds of a certain proposition, then we say that the truth of that proposition follows from the truth of the others.

(5.11)

If $p$ follows from $q$, the sense of ' $p$ ' is contained in the sense of ' $q$ '.

(5.121)

Finally, in accordance with the second, meaningtheoretically constrained general point, we should note that the notion of existence appropriate to states of affairs, namely that of obtaining, is not that of the existential quantifier: the latter is explained as a generalized truth-function of elementary propositions (5.52) and, as such, it already presupposes the notion of existence involved in the obtaining of the states of affairs.

Turning now to the general truth-maker scheme, Wittgenstein's terminology can profitably be transposed also to this context. What a truth-maker for a certain truth-bearer has to be, can be read off from the truthbearer sign itself; the relation between the proposition and its category of truth-makers is internal. Similarly, when the truth-bearer is made true by a given truthmaker, the connection between truth-maker and truthbearer is internal. Whether there exists a truth-maker or not, is not internally given in the proposition, but can only be determined through external research, that is, through a comparison with the world. In the Tractatus, when the truth-maker exists, that is, when the presented state of affairs obtains, the relation between this fact (that is, obtaining state of affairs) and the proposition is again an internal one. Thus, also in the Tractatus, two internal relations are at issue here: first, the relation between the proposition and its category of truth-makers and, secondly, the relation between the true proposition and its truth-maker. ${ }^{9}$ The application of the relevant notion of existence for the truth-makers is not internal to the proposition, however; in general, as we now know, truth can be read off from the symbol alone only in the exceptional case of tautological truth-functional combinations of propositions at the level of the propositional calculus. ${ }^{10}$

7.

The intuitionistic conceptions of meaning and truth that I consider here were made explicit around 1930 by Brouwer's first pupil, Arend Heyting, then a secondary 
school-teacher at Enschede in the eastern parts of the Netherlands. ${ }^{11}$ In this section I wish to summarize his views in order to show that his intuitionistic conception closely follows the general pattern set out above. ${ }^{12}$ We have three notions to consider: the truth-bearers, the truth-makers corresponding to a given truth-bearer and the notion of existence appropriate to the truth-makers.

The notion of truth-bearer chosen by Heyting is that of a proposition (French (1) proposition, German (2) (3) Aussage). A proposition is, or expresses, an expectation (French (1) attente, German (2) Erwartung), or a problem (French (1) problème, German (2) Problem (3) Aufgabe $).{ }^{13}$ As a result of familiarity with Oskar Becker's book Mathematische Existenz, Heyting notes that the word intention (German (2) Intention), from the phenomenological tradition, might best express what is at issue here. ${ }^{14}$

These various choices as to how to conceive of propositions are essentially equivalent, though, in that the resulting truth-bearer/truth-maker structures all turn out isomorphic. The truth-makers in question are as follows:

an expectation corresponds to a realization

(French (1) réalisation, German (2) Erfüllung)

an intention corresponds to a fulfilment

(German (2) Erfüllung),

a problem corresponds to a solution

(German (3) Lösung).

These links either were, or could have been forged in the phenomenological tradition, where the first chapter of Husserl's VIth Logical Investigation bears the title Bedeutungsintention und Bedeutungserfüllung, or by the Wittgenstein of note 9 . It is precisely at this point that intuitionism as primarily a philosophy of mathematics intervenes and contributes something essentially new:

a proposition corresponds to a proof.

In the primary sense, a proof, or perhaps better, a demonstration, is the (mental) act whereby the individual mathematician gets to know the truth of a certain proposition. The object of such an act of demonstration is the theorem proved that the proposition in question is true. These acts, proofs in the subjective sense, when completed, have no further existence, but they may leave tracks or traces. These traces, or proofs in the objective sense, are what we find written down in mathematical texts and what may be used by other mathematicians to carry out proofs in the subjective sense for the same theorem. ${ }^{15}$ These are not the proofs that are at issue in the intuitionistic truth-maker conception. Brouwer, in his famous demonstration of the Bar Theorem, introduced a novel notion of proof, namely proofs as mathematical objects. The German term used is that of a Beweisführung. From Brouwer's practice it is clear that his Beweisführungen are objects; they are named, restricted and transformed in much the same way as functions or well-founded trees are, as the following extracts show:

\footnotetext{
"the proof $h$ shows for an arbitrary element of $\sigma$ that is securable,"

"Let $h s n_{1} \ldots n_{r}$ be the specialization of $h$ that derives the securability of the element $F s n_{1} \ldots n_{r}$ "

"an arbitrary proof, when the connections used in it are decomposable into basic connections, can always (at least at the expense of brevity) be 'canonized' in such a way that its canonical form uses basic connections only"

"On the basis of a transfinite induction along $f s n_{1} \ldots n_{r}$ we see further that at every stage of the proof $k s n_{1} \ldots n_{r} \ldots .16$
}

The proofs intended by Heyting in the meaning explanations are also of this nature:

A proof of a proposition is a mathematical construction which can itself be treated mathematically. ${ }^{17}$

Furthermore:

every proposition, according to HEYTING, stands for the intention towards a mathematical construction that should meet certain conditions. A proof of a proposition consists in the actualization of the construction it demands. ${ }^{18}$

That the constructions intended in/demanded by propositions have to be mathematical objects is brought out quite clearly by the very first example offered by Heyting:

A proposition $p$, for example, "Euler's constant is rational" expresses a problem, or better still, a certain expectation (that of finding two integers $a$ and $b$ such that $C=a / b$ ) that can be realised or disappointed. ${ }^{19}$

What is demanded (intended, expected) by the proposition (problem, expectation, intention) is a certain mathematical object (a mathematical construction which can itself be treated mathematically), that satisfies certain conditions, depending on the proposition in question. The truth of the proposition is demonstrated by constructing a proof-object that meets the relevant 
conditions as determined by the proposition. Thus, in summary, we have to distinguish between

(i) proof-acts (demonstrations),

(ii) proof-traces, and

(iii) proof-objects.

It is the third notion that serves as truth-maker for the mathematical proposition on the intuitionistic conception of meaning and truth, and it is essential to recall this when disambiguating the formulations used in contemporary writings within the philosophy of mathematics. As already noted above, the object of an act of demonstration is the theorem proved. When it is made fully explicit, the theorem has the form

$$
a \text { is a proof (-object) of } A \text {, }
$$

where the construction $a$ is the object of an act of construction. An alternative, but, in the light of the preceding discussion, essentially equivalent, rendering is:

$a$ is a truth-maker for $A$.

With these formulations it is possible to make at least some sense of a couple of remarks of Wittgenstein's:

What is proved by a mathematical proof is set up as an internal relation and withdrawn from doubt.

Proof must show an internal relation, not an external one. ${ }^{20}$

On the above analysis, the internal relation shown by a proof (-act, demonstration) is that between truth-maker and truth-bearer, that is, between proof-object and mathematical proposition.

\section{8.}

The chosen truth-bearer/truth-maker relation of intuitionism is not original with intuitionism as we saw. Heyting transformed a well-known connection from within the phenomenological tradition, namely that between Intention and Erfüllung, by choosing the latter to be certain mathematical objects, which we now call proof-objects. The notion of existence appropriate to the chosen truth-maker relation is genuinely intuitionistic, though. Michael Dummett writes:

Hilbert's way of constructing arithmetical propositions involving quantification over all natural numbers concedes to them a great deal of informative content: it merely denies that they are statements assessable as true or false. . . For any particular natural number, say 103 , the proposition " $A(103)$ " is then uncontrover- sially an informative statement. The existential proposition "For some $n, A(n)$ " is taken by Hilbert to be an incomplete communication of any particular such instance: one is entitled to enunciate it if one knows of any specific number of which one can show that it satisfies the predicate " $A()$ ".

The intuitionists in effect accepted Hilbert's characterization of the meanings of the existential and universal quantifiers, but denied that statements formed by means of them were incapable of being subjected to negation or the other sentential operators. For them it was necessary only to explain the sentential operators in the same manner, rather than by truth-tables: that is, to give the meanings of the sentential operators by specifying, for each operator, what would justify the assertion of a statement of which it was the principal operator. ${ }^{21}$

Irrespective of its possible systematic merits, considered as a piece of history, this does not get matters quite right. The intuitionists did not have to borrow this notion of existence from the formalists; on the contrary, they took it ready made from within their own tradition. $^{22}$

The term "incomplete communication" used by Dummett to describe the formalist attitude to the existential proposition derives in this context from Kleene. ${ }^{23}$ It was used by him in conjunction with the term "partial judgement", simply as a translation of the German used by Bernays in Hilbert-Bernays:

An existential proposition regarding numerals, that is, a proposition of the form "there is a numeral $n$ with the property $A(n)$ ", is finitistically to be taken as a "partial judgement", that is, as an incomplete communication of a further determined proposition, $\ldots{ }^{24}$

The incomplete communication seems to be Bernays's own contribution. Partial judgement, though, goes back to Hilbert:

In general, an existential proposition has, from a finitist point of view, only meaning as a partial proposition, that is, as part of a further determined proposition, whose precise content is inessential for many applications. ${ }^{25}$

In an earlier article, Hilbert had already referred to the problem of negating the existential proposition and summarized the position as follows:

For finite totalities "there exists" and "there is available, at hand" mean the same; for infinite totalities only the latter concept is clear at once. ${ }^{26}$

This, however, is not the genesis of the formalist's view that existence leads to truncated non-propositional claims. Hilbert took this notion from his apostate pupil Hermann Weyl. 
Weyl had strong philosophical interests, especially geared towards phenomenology, and in 1918 he responded to the crisis in the foundations of mathematics with his predicativist manifesto Das Kontinuum. ${ }^{27}$ In the summer of 1919, Weyl had personal contact with Brouwer in Switzerland, where he got a private crash course of tutorials in intuitionism from the master himself. ${ }^{28}$ The result was dramatic: Weyl decided to jettison his own project and to join forces with Brouwer. This he did publicly in a series of provocative lectures, Über die neue Grundlagenkrise der Mathematik, delivered at Zürich in 1920. Here, in his exposition of basic intuitionistic principles, Weyl introduced some novelties:

An existential Proposition - for instance, "there is an even number" - is not at all a proper judgement that expresses a state of affairs; Existential states of affairs are an empty invention of logicians. " 2 is an even number": that is a real judgement that expresses a state of affairs; "there is an even number" is only a judgement-abstract that has been obtained from this judgement. ${ }^{29}$

This - Weyl's judgement abstract - then, is the formalist's source for his incomplete communication. Thus, as stated above, it is not in agreement with the facts to say that the intuitionists obtained their notion from the formalists. On the contrary, they already had it. ${ }^{30}$

Recently Per Martin-Löf has given a streamlined version of this notion of existence. ${ }^{31}$ When $\alpha$ is a category, a general concept, then

\section{$\alpha$ exists}

is a judgement. Which judgement it is, is explained by telling what knowledge is expressed by, or in, the judgement in question. In other words, the judgement is explained by telling what knowledge one has to have in order to have the right to make it. Here, in order to have the right to make the judgement

$\alpha$ exists,

it is required that one has made some judgement

$$
a: \alpha^{32}
$$

that is, in order to ascribe existence to a general concept one has to know an object falling under the concept in question.

In conclusion, then, one should note that also in the present intuitionistic case, the notion of existence that is involved in the truth-maker analysis, namely the Weyl-Hilbert conception of existence-claims as elliptical, or truncated,

\section{$S$ is $P$}

judgements, is clearly non-propositional in nature. Accordingly, it is different from the existential quantifier.

\section{9.}

The notion of truth that is applicable to intuitionistic propositions, finally, can now be pieced together from the notion of proof-object and the notion of existence:

$$
\text { the proposition } A \text { is true }
$$$$
=
$$

the concept proof-object of $A$ exists.

It should be noted that what has been explained here is the notion of truth simpliciter. This is the primary notion of truth that is involved at the most basic level, for instance in the formulation of a consequence

$$
A_{1} \text { true }, \ldots, A_{k} \text { true } \Rightarrow C \text { true. }
$$

Since consequences can also hold between propositions which are in fact not true, we see here that from the very formulation

\section{A true}

of a proposition's being true simpliciter, it does not follow that the desired proof-object is there to be found. As Martin-Löf has explained, the intuitionist needs to distinguish between this notion of truth simpliciter, potential truth, when a proof-object can be found, and actual truth, when a proof-object has been found. ${ }^{33} \mathrm{I}$ have dealt with a number of the resulting complexities at some length elsewhere and accordingly $I$ here confine myself with a reference to Martin-Löf's original paper and my own earlier remarks. ${ }^{34}$

\section{Notes}

* The present paper was written during a sabbatical leave while visiting the Department of Philosophy, University of Stockholm, I am indebted to the Department, as well as to the Wenner-Gren Foundation, Stockholm, for financial support that made the visit possible. Per Martin-Löf read the paper in manuscript and suggested a number of improvements. Unless otherwise indicated the English translations are my own.

1 Elements of Intuitionism, Oxford U. P., 1977, p. 6.

2 Michael Dummett considers the principle $C$ (correspondence):

If a statement is true, there must be something in virtue of which it is true, 
which principle is clearly nothing but a formulation of a truth-maker condition on truth, in his 'What is a Theory of Meaning? II', in The Seas of Language, Oxford U. P. (1993), p. 53, first published in G. Evans and J. McDowell (Eds.), Truth and Meaning, Oxford U. P. (1976). As far as I know, the apt "truth-maker" terminology was introduced by K. Mulligan, P. Simons, and B. Smith, "Truth-makers", Philosophy and Phenomenological Research XLIV (1984), 287-321.

3 'The nature of truth', in: G. W. Leibniz, Philosophical Writings (Ed. G. H. R. Parkinson), Everyman's Library, J. M. Dent \& Sons, London (1973), pp. 93-96, at p. 93.

4 Tractatus Logico-Philosophicus, Routledge and Kegan Paul, 2nd edition (1961), English translation: David Pears and Brian McGuinness, reprinted with corrections, London, 1974.

5 'Language and truth', in The Seas of Language, op. cit., note 2, pp. $117-146$, p. 118 , originally published in R. Harris (Ed.), Approaches to Language, Pergamon Press, Oxford (1983). Similar considerations can be found in Michael Dummett, The Logical Basis of Metaphysics, Duckworth, London (1991, especially in the section 'The concept of truth and its habitat', pp. 157-160.

6 'Language and truth', op. cit., note 5, p. 119.

7 The Logical Basis of Metaphysics, op. cit., note 5, p. 160.

8 Op. cit., loc. cit., note 7 .

9 In Wittgenstein's Lectures, Cambridge 1930-1932 (ed. Despond Lee), Blackwell, Oxford, 1980, Lecture A IV, p. 9, we find:

Ogden \& Richards and Russell consider that the relation of proposition to fact is an external relation; this is not correct. It is an internal relation. (An internal relation cannot be otherwise; it is given in terms of the terms involved, in the nature of proposition and fact.) On Russell's view you need a tertium quid besides the expectation and the fact fulfilling it; so if $I$ expect $x$ and $x$ happens, something else is needed, e.g. something that happens in my head, to link expectation and fulfilment. But how do I know that it is the right something? Do I, on the same principle, need a fourth something? If so, we have an infinite regress, and I can never know that my expectation has been fulfilled. (We can always ask for a further description of any criterion given of meaning or fulfilment; which produces an infinite regress.)

10 Wittgenstein was aware of the fact that, in his Tractarian philosophy of logic, he had not made hard the crucial point that every proposition of logic must be recognizable as such from the symbol itself. As soon as we exceed the means of expression available in propositional logic problems arise that were clearly felt by Wittgenstein. Thus, for instance, in an undated letter to Russell (No. 24 in Ludwig Wittgenstein: Briefe, Herausgegeben von B. F. McGuinness and G. H. von Wright, Suhrkamp, Frankfurt, 1980) Wittgenstein is at pains to explain his general method for determining whether a proposition is a tautology. He then claims:

Of course the rule I have given applies first of all only for what you called elementary prop(osition)s. But it is easy to see that it must also apply to all others. For consider your two Pps in the Theory of app[arent] var[iable]s *9.1 and *9.11. Put these instead of $\phi(x),(\exists y) \cdot \phi(y) \cdot y=x$ and it becomes obvious that the special cases of these two Pps like those of all the previous ones becomes tautologous if you apply the ab-Notation. The ab-Notation for Identity is not yet clear enough to show this clearly but it is obvious that such a Notation can be made up.
Contrary to what Wittgenstein thought at this stage, the difficulty involving the inclusion of identity and quantification cannot be resolved, but falls prey to the Church-Turing Theorem concerning the undecidability of predicate logic.

A second example of Wittgenstein's awareness of the latent difficulties at this point is provided by the Tractatus, thesis 6.1203 , where a decision-method is presented which is essentially a variant of the ab-Notation of the earlier notes, and which allows us eine Tautologie als solche zu erkennen, but only for those cases when the tautology in question contains no Allgemeinheitsbezeichnung, that is, when it contains no quantifiers.

11 The crucial publications are:

(1) 'Sur la logique intuitionniste', Acad. Roy. Belgique, Bull. $\mathrm{Cl}$. Sci. V, 16 (1930), 957-963.

(2) 'Die intuitionistische Grundlegung der Mathematik', Erkenntnis 2 (1931), 106-115. English translation 'The intuitionist foundations of mathematics', pp. $42-49$, at pp. $47-48$ in P. Benacerraf and Hilary Putnam (eds.), Philosophy of Mathematics, Prentice-Hall, Englewood Cliffs, New Jersey, 1964.

(3) Mathematische Grundlagenforschung. Intuitionismus. Beweistheorie., Julius Springer, Berlin, 1934,

and they will be cited by their numbers in the above list.

12 I have gone into Heyting's formulations in considerable detail in a number of earlier publications:

(a) 'Constructions, proofs and the meaning of the logical constants', Journal of Philosophical Logic 12 (1983), 151-172.

(b) 'Questions of proof', Manuscrito (Campinas, S. P., Brazil), XVI (1993), 47-70.

(c) 'Proof-theoretical semantics and Fregean identity-criteria for propositions', forthcoming in The Monist, July 1994.

13 The term Aufgabe was introduced by Kolmogoroff in his important 'Zur Deutung der intuitionistischen Logik', Mathematische Zeitschrift 35 (1932), 58-65. This paper was written on the basis of reading (1) and correspondence with Heyting, as well as seeing (2) during the time of the printing process. The relevant letters have been published in A. S. Troelstra, 'On the early history of intuitionistic logic', preprint, Amsterdam 1988.

14 Jahrbuch für Phenomenologie und Philosophische Forschung 8 , 1927, Zweiter Halbband. Also in a separate edition, Max Niemeyer Verlag, Tübingen, 2nd edn, 1973.

15 I am indebted to Per Martin-Löf for drawing my attention to the distinction between subjective and objective proofs.

${ }^{16}$ L. E. J. Brouwer, 'Beweis das jede volle Funktion gleichmässig stetig ist', Proceedings of the Royal Dutch Academy 27 (1924), 189-193, at pp. 189-190.

17 (2), p. 48 (German original p. 114).

18 (3), p. 14.

19 (1), p. 958.

20 Remarks on the Foundations of Mathematics, 3rd rev. ed., Oxford, Basil Blackwell, 1978, edited by G. H. von Wright, R. Rhees, and G. E. M. Anscombe, translated by G. E. M. Anscombe, pp. 363-364.

21 'The source of the concept of truth', in The Seas of Language, op. cit., note 1 , pp. 188-201, at pp. 188-190. Originally published in G. Boolos (ed.), Meaning and Method: Essays in Honor of Hilary Putnam, Cambridge U. P. (1990). 
22 This very point is also made by Mathien Marion, 'Wittgenstein and Finitism', forthcoming in Synthese 1994.

23 'On the interpretation of intuitionistic number theory', Journal of Symbolic Logic 10 (1945), 109-124, at p. 109.

24 Grundlagen der Mathematik I, Julius Springer, Berlin (1934), p. 32. German original:

Ein Existenzsatz uber Ziffern, also ein Satz von der Form "es gibt eine Ziffer $n$ von der Eigenschaft $A(n)$ ", is finit aufzufassen als ein "Partialurteil", d. H. als eine unvollständige Mitteilung einer genauer bestimmten Aussage, ...

25 'Über das Unendliche', Mathematische Annalen 95 (1926), 161-190, at p. 173 (my italics). German original:

Allgemein hat vom finiten Standpunkt eine existentiale Aussage, von der Form: es gibt eine Zahl von der und der Eigenschaft, nur als Partialaussage einen Sinn, d. h. als Teil einer näher bestimmten Aussage, deren genauer Inhalt jedoch für viele Anwendungen unwesentlich ist.

26 'Die logischen Grundlagen der Mathematik', Gesammelte Abhandlungen III, Julius Springer Berlin (1935), 178-191, at p. 182. (Original publication in Mathematische Annalen 88 (1923).) German original:

Bei endliche Gesamtheiten sind "es gibt" und "es liegt vor" einander gleichbedeutend; bei unendlichen Gesamtheiten ist nur der letztere Begriff ohne weiteres deutlich.

27 Leipzig, 1918.

28 Dirk van Dalen, Hermann Weyl's Intuitionistic Mathematics, Utrecht University, Logic Group Preprint No. 94, July 1993.

${ }^{29}$ Mathematische Zeitschrift 10(1921), 39-79, at p. 54. German original:

Ein Existenzialsatz - etwa "es gibt eine gerade Zahl" - ist überhaupt kein Urteil im eigentlichen Sinne, das einen Sachverhalt behauptet; Existential-Sachverhalte sind eine leere Erfindung der Logiker. " 2 ist eine gerade Zahl": das ist ein wirkliches, einem Sachverhalt Ausdruck gebendes Urteil; "es gibt eine gerade Zahl" is nur ein aus diesem Urteil gewonnenes Urteilsabstrakt.

30 A demand in general terms that existence claims be substantiated through explicit construction can, of course, be found in Brouwer's early writings, for instance 'Die moeglichen Maechtigkeiten', in: Atti IV Congr. int. matematici Bologna (1908), pp. 569-571. Nevertheless, Weyl seems to be the first intuitionist to comment explicitly upon the exceptional, elliptical, character of existence claims. However, apart from such internal examples from intuitionistic mathematics, Weyl could also have drawn upon other philosophical sources.

In his Allgemeine Erkenntnislehre, Julius Springer, Berlin (1918), $\S 13$, p. 85 (second edition, 1925: p. 95, Suhrkamp Taschenbuch 269, Frankfurt, 1979: p. 126), Moritz Schlick remarks concerning judgements of the form "Some $S$ are $P$ ":

Practically important as they may become, scientifically they have only a provisional meaning, so to speak, and, therefore, within a strict system, they do not have a place. These judgements, namely, only subsume part of the objects of a certain concept under another concept, and in such a way that it is left undetermined what part of the objects is intended. In reality a particular judgement can be advanced only when we actually know such $S$ that are $P$. Always, also in practice, the source of the truth of a particular judgement lies in, and must be possible to trace to, the knowledge of quite specific $S$. Thus, it is an incomplete abbreviation of the judgement " $S_{1}$ and $S_{2}$ and $S_{3}$ etc. are $P$ ". Everywhere, when the $S$ cannot be indicated individually (when one has forgotten them or trusted the statements of others), the judgement is not certain. In order to show its validity, one always has to return to the individual objects that constitute the subjectconcept "Some $P$ ", and thereby one replaces the particular judgement with a general. In the place of, for instance, the judgement "some metals are lighter than water" steps the other: "Potassium, sodium and lithium are lighter than water"; and only the latter has full scientific value.

German original:

So wichtig sie in der Praxis werden mögen, wissenschaftlich haben sie nur gleichsam eine vorläufige Bedeutung, und daher in einem strengen System keinen Platz. Diese Urteile subsumieren nämlich nur einen Teil der Gegenstände eines bestimmten Begriffes unter einem andern Begriff, und zwar so, dass sie unbestimmt lassen, welcher Teil der Gegenstände gemeint ist. In Wirklichkeit lässt sich ein partikuläres Urteil nur aufstellen, wenn wir tatsächlich solche $S$ kennen, die $P$ sind. Stets, auch in der Praxis, liegt der Quelle der Wahrheit eines partikulären Urteils in dem Wissen um ganz bestimmte $S$ und muss sich bis zu diesen zurückverfolgen lassen. Es ist also nur eine unvollkommene Abkürzung für das Urteil " $S_{1}$ und $S_{2}$ und $S_{3}$ etc. sind $P$ ". Überall, wo die $S$ nicht einzeln angebbar sind (wo man sie etwa vergessen hat oder fremden Aussagen vertraut), ist auch das Urteil nicht gewiss. Um seine Gültigkeit darzutun, muss man stets auf die einzelnen Gegenstände zurückgehen, die den Subjektbegriff "einige $S$ " ausmachen, und damit ersetzt man eben das partikuläre Urteil durch ein allgemeines. An die Stelle etwa des Urteils "Einige Metalle sind leichter als Wasser" tritt das andere: "Kalium, Natrium und Lithium sind leichter als Wasser". (my boldface)

In the first edition of Raum-Zeit-Materie (Julius Springer, Berlin, 1918), Weyl does cite Schlick's Raum und Zeit in der gegenwärtigen Physik (Julius Springer, Berlin, 1917), whence we know that Schlick was an author Weyl knew at the appropriate time. Also, the very last page of Weyl's book contains a publisher's announcement of the forthcoming book Allgemeine Erkenntnislehre by Moritz Schlick. Furthermore, Weyl kept track of Schlick's writings: in the fourth edition of Raum-Zeit-Materie (1921), the reference to Schlick has been updated to the third edition of 1920. Also in Philosophie der Mathematik und Naturwissenschaft, Handbuch der Philosophie (Abt. II, Heft 1, München und Berlin, 1921), Weyl twice refers to the 1918 edition of Allgemeine Erkenntnislehre. Thus, on balance, it seems likely that Weyl knew Schlick's text when he gave his lectures at Zürich.

Another possible source is the phenomenological tradition in the guise of Alexander Pfänder's Logik, published in 1921, but written for Husserl's 70th birthday in 1919. Of this I have only seen the second edition (Max Niemeyer, Halle, 1929), where Pfänder writes (p. 63):

Es wäre zu gendankenlos, von der allgemeinen Formel des Urteils 
" $S$ ist $P$ " auszugehen, und aus ihr das Existenzialurteil als prädikatloses Urteil einfach dadurch abzuleiten, dass man das " $P$ " weglässt und den Rest " $S$ ist" als Formel des Existenzialurteils nimmt. Denn was man durch jene Weglassung des " $P$ " in Wahrheit gewinnt, ist uberhaupt kein Urteil mehr, sondern ein Urteilsbruchstück.

English translation:

It would be too thoughtless simply to start with the general formula of the judgement " $S$ is $P$ " and derive the existential judgement from it as a predicateless judgement through the removal of " $P$ " and putting the rest " $S$ is" as the formula for the existential judgement. Because, in truth, what one gets through this removal of " $P$ " is no longer a judgement anymore, but rather a judgementfragment.

If formulations such as this were current in the phenomenological circles in which Weyl and his wife moved, they certainly constitute another possible, or even likely, source for his notion of an Urteilsabstrakt.
31 'Analytic and synthetic judgements in type theory', forthcoming in the proceedings of the workshop on Kant and Contemporary Epistemology, Florence, 27-30 May, 1992.

32 In words: $a$ is an object of category $\alpha$.

33 'A path from logic to metaphysics', in G. Corsi and G. Sambin (eds.), Atti del Congresso Nuovi Problemi della Logica e della Filosofia della Scienza, Viareggio, 8-13 gennaio, 1990, CLUEB, Bologna, 1991, pp. 141-149.

34 'Vestiges of realism', in The Philosophy of Michael Dummett, edited by Brian McGuinness and G. Oliveri, Kluwer, Dordrecht, 1994 p. 163, where an example involving a consequence between false propositions is worked out in detail.

Faculty of Philosophy

Leyden University

P.O.Box 9515

2300 RA Leiden

The Netherlands 